\title{
DESAFIOS TEÓRICOS PARA OS ESTUDOS DE RELIGIÃO, MÍDIA E CULTURA NA CONTEMPORANEIDADE
}

\author{
- KARINA KOSICKI BELLOTTI ${ }^{1}$
}

1Doutora em História Cultural (Unicamp), Professora do Departamento de História e do Programa de Pós-Graduação em História da Universidade Federal do Paraná (UFPR) e membro do grupo de pesquisa MIRE - Mídia, Religião e Cultura, da Intercom.

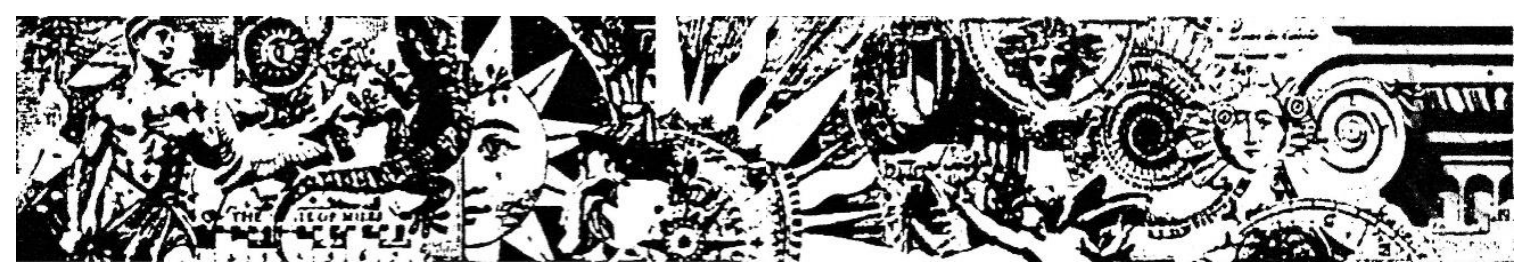

Resumo: Neste artigo são discutidos alguns desafios de se pesquisar as relações entre religião, mídia e cultura no contexto contemporâneo. $O$ texto divide-se em cinco questionamentos: primeiro, como surgiram os estudos sobre estas relações, quem tem as conduzido e como. Para isso, abordaremos 0 campo de estudos de Religião, Mídia e Religião desenvolvidos nos Estados Unidos a partir dos anos 1980, seus principais objetos e problemas, a partir de Stewart Hoover e David Morgan. Segundo, discutirei as implicações de uma conceituação ampla sobre religião os estudos de religião, mídia e cultura. Em terceiro lugar, seguem reflexões sobre conceitos de cultura a partir dos Estudos Culturais britânicos, a Antropologia Cultural e a História Cultural. Em seguida, as relações entre comunicação e religião, apresentando exemplos de trabalhos feitos dentro e fora do Brasil realizados nesta área. Por fim, quais os desafios a serem enfrentados pelos estudos mais recentes sobre religião, mídia e cultura.

Palavras-chave: Religião, Mídia, Comunicação, Cultura.

\section{THEORETICAL CHALLENGES FOR THE STUDIES ON RELIGION, MEDIA, AND CULTURE IN THE CONTEMPORARY AGE}

Abstract: In this article, there will a discussion on certain challenges in the research on the relation between religion, media and culture in the contemporary context. This text is divided in five main problems: first, how did the field of studies on these relations emerge, who has been conducting them and how. Thus, i will approach the field of studies on religion, media, and culture developed in the united states of america by the 1980s, its main objects and problems, referring to the works of stewart hoover and david morgan. Secondly, i will discuss the implications of a broader concept of religion on the 
studies of religion, media and culture. Third, i will bring reflections on the notions of culture by the british cultural studies, the cultural anthropology and the cultural history. Then, follow the relations between communication and religion, presenting some examples of researches made within and outside brazil. Finally, what are the challenges to be faced by the recent studies on religion, media, and culture.

Keywords: Religion, media, communication, culture.

\section{DÉFIS THÉORIQUES DES ÉTUDES SUR LA RELIGION, LES MÉDIAS ET LA CULTURE À L'ĖRE CONTEMPORAINE}

Resumé: Dans cet article, nous discutons de certains défis de la recherche sur les relations entre religion, médias et culture dans le contexte contemporain. Le texte est divisé en cinq questions: premièrement, comment ont été menées les études sur ces relations, qui les a conduites et comment. Pour cela, je vais approcher le domaine d'études de la religion, des médias et de la religion développé aux états-unis à partir des années 1980, ses principaux objets et problèmes, se référant aux travaux de stewart hoover et david morgan. Deuxièmement, je discuterai des implications d'une large conceptualisation sur la religion, les religions, les médias et la culture. Troisièmement, ils réfléchissent aux concepts de culture issus des études culturelles britanniques, de l'anthropologie culturelle et de I'histoire culturelle. Ensuite, les relations entre communication et religion, en présentant des exemples de travaux réalisés à l'intérieur et à l'extérieur du brésil dans ce domaine. Enfin, quels sont les défis à relever pour les études les plus récentes sur la religion, les médias et la culture.

Mots-clés: Religion, médias, communication, culture.

\section{Introdução}

Desde o século XIX, as sociedades ocidentais têm seu cotidiano permeado pelos mais variados meios de comunicação, que ajudam a perfazer suas percepções, opiniões e sentimentos sobre a sua realidade vivida. Isso inclui as dimensões religiosas e espirituais de indivíduos, grupos e instituições sociais, permeados por linguagens, representações e estruturas de comunicação eletrônica, digital e tradicional. Tendo em vista este aspecto da vida religiosa, surgiram os estudos sobre Religião, Mídia e Cultura nos anos 1980 nos Estados Unidos, primeiramente na área de Comunicação Social, e depois ampliados para outras áreas do conhecimento e outros países. Desta forma, neste artigo, apresentarei alguns desafios de se pesquisar as relações entre religião, mídia e cultura a partir do contexto contemporâneo.

Falo a partir de dois lugares sociais e acadêmicos - dos estudos historiográficos e dos estudos de religião, mídia e cultura, que é mais amplo do que o campo historiográfico, constituindose em campo multidisciplinar e em plena construção. Sou historiadora de formação e de profissão, conduzo pesquisa sobre mídia evangélica no Brasil e nos Estados Unidos nos século XIX a XXI e pertenço ao grupo de pesquisa criado em 2015 e registrado no CNPq intitulado Mídia, Religião e Cultura, ligado à Intercom (Sociedade Brasileira de Estudos Interdisciplinares de Comunicação) e 
à Associação Internacional de Mídia, Religião e Cultura, coordenado pela Profa. Dra. Magali do Nascimento Cunha e Prof. Dr. Jorge Miklos². Este artigo divide-se em cinco questionamentos que partem da problematização das relações entre religião, mídia e cultura: primeiro, como surgiram os estudos sobre estas relações, quem tem as conduzido e como? Em segundo lugar, o que é religião para estes estudos? Em terceiro, o que é cultura? Em seguida, o que é comunicação e religião e quais exemplos de trabalhos temos nesta área, e como eles ajudam a problematizar esta área? Por fim, quais os desafios a serem enfrentados pelos estudos mais recentes? Esta reflexão não pretende de forma alguma cobrir um campo em expansão, mas apontar algumas direções teóricas presentes nos estudos mais recentes, e as carências e os desafios a serem enfrentados por futuras pesquisas.

\section{Religião, Mídia e Cultura}

Os estudos sobre religião, mídia e cultura surgem com esta denominação nos Estados Unidos, a partir dos anos 1980, com os trabalhos de Stewart Hoover (1985) e Peter Horsfield (1986) sobre tele-evangelistas estadunidenses, populares desde os anos 1970. Eram análises que partiam da Comunicação Social para observar a construção da chamada Igreja Eletrônica, um fenômeno próprio do contexto dos Estados Unidos, em que pastores tinham como ministério a comunicação pela televisão, rádio, e mídia impressa. Dessa forma, eram marcadas pela predominância de casos cristãos, e pela ideia de que as mídias transmitiam mensagens religiosas, restringindo o estudo aos agentes religiosos que possuíam autoridade na produção destas mensagens.

No Brasil, um marco nestes estudos foi o livro "A Igreja Eletrônica no Brasil" (1986), de Hugo Assmann, que fez uma análise da presença de pastores e padres na televisão brasileira, comissionado pela Associação Mundial de Comunicação Cristã (WACC). 0 estudo trouxe uma visão bastante influenciada pela Teologia da Libertação e do marxismo para criticar o uso dos meios de comunicação por agentes religiosos - segundo estas visões, os meios de comunicação serviam aos interesses dos donos dos meios de produção, e por isso, não eram veículos de reflexão e de resolução dos profundos problemas sociais, e sim, meios de alienação social. Dessa forma, Assmann criticou a forma como as religiões mais pareciam resolver problemas pontuais

\footnotetext{
${ }^{2}$ Cf. http://gpcomreligiaointercom.blogspot.com/. Acesso em 25 de novembro de 2018.
} 
daqueles que recorressem a elas do que propriamente transformassem a realidade a partir da aplicação da mensagem cristã.

O trabalho de Assmann foi referenciado posteriormente por análises sociológicas sobre 0 crescimento evangélico a partir dos anos 1990, mas foi somente a partir do final dos anos $1990 \mathrm{e}$ início dos anos 2000 é que observamos no Brasil uma produção maior de pesquisas que abordassem as relações entre religião e mídia de maneira central, e não somente como um instrumento auxiliar no crescimento desta ou daquela denominação. Ainda assim, durante muito tempo, dos anos 1980 e 1990, os trabalhos que abordavam religiões que estivessem presentes na mídia dificilmente traziam considerações sobre esse aspecto, ou quando muito, era abordada de maneira breve - mais mencionada do que problematizada. Um trabalho que, na área dos estudos do pentecostalismo, trouxe maior reflexão sobre a questão da mídia e da propaganda foi a tese de doutorado do sociólogo Leonildo Silveira Campos, sobre a Igreja Universal do Reino de Deus, "Teatro, Templo e Mercado" (1997). No caso de estudos sobre o catolicismo, destacamos o trabalho de Paula Montero e Ralph Della Cava, "E o verbo se faz imagem...Igreja Católica e os Meios de Comunicação no Brasil (1969-1989)" (1991). Estes são apenas alguns trabalhos - ainda está para ser feito um levantamento do estado da arte e das produções acadêmicas já lançadas sobre estas questões no Brasil.

No que se refere a estudos que lidem de maneira central com as relações entre mídia e religião, foi fundamental o pioneiro trabalho de Magali do Nascimento Cunha (2007), "A explosão gospel", estudando a criação da cultura gospel no meio evangélico brasileiro a partir de referenciais comunicacionais e das ciências sociais, tais como Nestor Canclini (2015) e o conceito de hibridismo cultural, Douglas Kellner (2001) e a cultura da mídia, dentre muitos outros. Sua inovação foi analisar a cultura gospel como expressão aglutinadora do heterogêneo conjunto de denominações evangélicas, estabelecendo formas de recepção, entretenimento e consumo como forma de participação dos evangélicos do reino dos céus na terra.

Neste mesmo período, na virada dos anos 1990 para 2000, estrutura-se a Associação Internacional de Religião, Mídia e Cultura, sediado até hoje na Faculdade de Jornalismo e Comunicação da Universidade do Colorado em Boulder ${ }^{3}$. Ao promover a cada dois anos um simpósio internacional - que já passou pelo Brasil em 2008 - essa associação tem agrupado pesquisadoras e pesquisadores das relações entre religião, mídia e cultura advindos de diferentes áreas do conhecimento e não somente da comunicação: ciências sociais (sociologia, antropologia, ciência política), história, geografia, teologia, ciências da religião, dentre muitas outras. A

${ }^{3}$ Cf. https://www.colorado.edu/cmrcl. Acesso em 28 de outubro de 2018. 
diversificação de olhares reflete a multiplicidade de aspectos observados sobre as expressões religiosas e espirituais no mundo atual e nos mundos de outras temporalidades, ampliando a concepção do que se entende por religião. Alguns desses trabalhos estão registrados em livros como "Practicing Religion in the Media Age" (HOOVER; CLARK, 2002). Tal pluralidade suscita 0 questionamento sobre o que é considerado religião nesses estudos - pergunta esta que está no horizonte de diferentes áreas de estudo das religiões no tempo recente.

\section{0 que é religião?}

O historiador Marc Bloch atestou em seu famoso livro "Apologia da História" (2001), escrito em 1944, que a história produzida sobre um determinado evento passado sempre terá influência de inquietações e perguntas feitas no presente - o espaço-tempo em que se situa a historiadora ou o historiador. Desta forma, podemos compreender como o conceito de religião tem se transformado desde que as disciplinas de história das religiões e de ciência das religiões se constituíram desde meados do século XIX na Europa. Em especial se considerarmos que 0 conceito advém da tradição judaico-cristã de um conjunto de doutrinas e de práticas que visam religar os seres humanos a uma divindade criadora. Tal concepção foi amplamente difundida por missionários católicos (em especial desde século XVI) e protestantes (mais frequentemente a partir do século XIX) para povos que desconheciam esse tipo de noção religiosa, e que possivelmente tinham suas próprias noções de sagrado ou de divindades.

Desta forma, saber desta origem e desta marcação histórica em nossas concepções ocidentais de religião é fundamental para ampliar este conceito para outras realidades e temporalidades - ou ao menos reconhecer que essa ampliação está sujeita a problematizações. Assim, tomamos do historiador Angelo Brelich (1970), da Escola Italiana de História das Religiões, a ideia de que religião não se define de maneira apriorística nem essencial, devendo ser entendida na pluralidade de suas expressões - religiões - e no seu caráter conceitual, construído a posteriori por estudiosos das religiões, que observam como determinadas sociedades atribuem características religiosas a determinados aspectos de sua vivência (ADOLIN, 2008, p. 28-29; BRELICH, 1970). Não que os estudiosos e estudiosas das relações entre religião, mídia e cultura de fato tomem para si somente esta definição - mas é interessante partir dela, pois muitos desses estudos, feitos dentro e fora do Brasil, consideram as religiões na sua diversidade de expressões e vivências, entendo-as como uma construção social e histórica. 
A essa concepção soma-se o questionamento do eurocentrismo e do etnocentrismo predominantes nas ciências humanas e nas relações geopolíticas até meados do século XX. Causaram um profundo impacto nas concepções de sociedade os processos de descolonização da Ásia e da África, os movimentos por direitos civis nos Estados Unidos, e os movimentos de reconhecimento de pluralidades culturais, sexuais, raciais. Caminhando para um processo de globalização econômica e cultural ao final do século XX, os pesquisadores e as pesquisadoras das ciências humanas, e das religiões em particular, tornam-se cada vez mais sensíveis ao pluralismo cultural e às desigualdades de poder que o permeiam.

No que se refere aos estudos de religiões, isso se reflete em uma concepção problematizada do que constitui religião, quem a constitui e como a constitui. Assim, os estudos de religião, mídia e cultura seguem tendências gerais nos estudos de religiões que entendem as religiões como construções sociais e históricas, sujeitas às forças tanto de mudança quanto de permanência. Isso implica considerá-las não somente nos seus aspectos doutrinários e institucionais, mas também nos seus elementos e manifestações populares, dentro e fora das instituições, com sua plasticidade moldada pelos sujeitos que creem e até pelos que não creem ou creem de vez em quando, quando Ihes convém. Há que se considerar as assimetrias de poder dentro das instituições religiosas, além do contexto de desinstitucionalização, de destradicionalização e de maior autonomia religiosa individual demonstram que as possibilidades de vivência, pensamento e sentimento religiosos a serem contemplados pelos estudiosos precisa sempre ser ampliado e revisto.

Assim, dentro da definição de religião, entram as práticas de devoção, de dissenso, de reapropriação das tradições, dos símbolos e das narrativas religiosas. Os estudos sobre mídia, religião e cultura podem adotar a perspectiva de que as religiões são tanto aquilo que as instituições e suas autoridades determinam, quanto aquilo que seus fiéis professam, fazem, expressam em sua esfera pública e privada. Se o paradigma da secularização compreende na esfera ocidental a separação entre Igreja e Estado, e entre a religião e outras esferas da vida social, o que se observa é que as fronteiras entre essas separações historicamente estiveram borradas e intercambiáveis. Essa noção mais ampliada do que é religião possui relação com as contribuições dos estudos sobre cultura no século XX, e a proeminência que ela adquire social e politicamente. 


\section{0 que é cultura?}

O conceito de cultura possui múltiplas definições - certamente, os pesquisadores de mídia, religião e cultura não possuem uma visão consensual sobre este conceito. Porém, são fundamentais as influências dos Estudos Culturais - britânicos e feitos fora da Grã-Bretanha - e da Antropologia Cultural para a forma como a cultura tem sido estudada na academia. $O$ historiador David Morgan (2008, pp. xi-xv), um dos expoentes nos estudos de religião, mídia e cultura, afirmou que o fato de os Estudos Culturais britânicos se originarem do marxismo levou à negligência da abordagem de temas ligados à religião. Porém, vale retomar algumas considerações desta corrente para fazermos algumas relações com os estudos de religião.

Raymond Williams (2002), no livro "Palavras-chave", escreveu que desde os anos 1950 tinha observado o quanto se falava cada vez mais sobre cultura das universidades britânicas, e por isso, decidiu analisar o que era esta cultura e quais as suas formas na sociedade. Ainda que os resultados deste estudo se referissem diretamente à realidade britânica e sob um prisma marxista, nos livros "Cultura e Sociedade" (1969) e "Palavras-chave", suas conclusões ajudam até hoje a refletir sobre cultura. Algumas definições dão conta de que a cultura pode ser entendida como expressão artística, como expressão de um modo de vida de um povo ou grupo social, como algo a ser cultivado - um conhecimento, ou até a civilidade. Outra contribuição dos estudos culturais é sua perspectiva voltada para a cultura produzida e consumida pelas classes populares, em oposição a uma cultura que se coloca erudita ou "superior", o que implica voltar o olhar para aqueles que nunca foram vistos como produtores de uma cultura representativa, na visão de elites políticas e intelectuais. Contudo, esses estudos nunca trabalharam com assuntos religiosos - se ajudaram a desenvolver uma perspectiva ampliada sobre cultura por um lado, esse olhar não incluiu a religião, mesmo nas suas formas populares.

Já a antropologia cultural de Clifford Geertz (1989) contribui com a concepção de que a cultura é um sistema simbólico que ganha sentido a partir dos usos e representações de um determinado grupo social. A religião é vista como um sistema simbólico a ser compreendido pela própria forma como seus aderentes e autoridades a cultivam. Essa concepção de cultura impactou muito a corrente historiográfica da História Cultural, que há pelo menos 30 anos tem se dedicado a estudar as representações simbólicas e as narrativas da realidade produzidas pelos indivíduos, pelos grupos e pelas instituições sociais. 
A História Cultural tem se constituído como historiografia especializada em uma abordagem cultural - não se trata de uma história da cultura (ou seja, uma história de objetos culturais), mas de uma perspectiva que privilegia as construções, narrativas, imaginários e representações culturais sobre determinados fatos históricos e fenômenos sociais, políticos, econômicos - e culturais (HUNT, 1995). Segundo Peter Burke (2008), a História Cultural que se desenvolve a partir da Europa - em especial na França - ligada à terceira geração da corrente historiográfica da Escola dos Annales, a partir dos anos 1980. Não que a cultura não estivesse presente (seja como objeto, seja como abordagem) em outras épocas - Burke apontou trabalhos dos séculos XVIII e XIX - o que ele chama de História Cultural - que contemplavam questões simbólicas e de imaginários, mas na historiografia professional, elas foram marginalizadas em detrimento de temas sociais, políticos e econômicos. O que Burke (2008) denomina Nova História Cultural refere-se também a um tipo de história antropológica (BURKE, 2000, pp. 231-268), de certa forma herdeira da primeira História Cultural, e sujeita a uma diversificação maior de objetos e problemáticas.

Uma das maiores referências no Brasil desta História Cultural é o historiador Roger Chartier (2003), especialista em história da leitura e dos leitores, que retrabalhou o conceito de representação coletiva advinda da antropologia como representação social, no artigo "A História como Representação" (2003, pp.61-79). Para Chartier, a representação confere sentido ao vivido, ao "real", reforçando identidades culturais e sociais coletivas, e proporcionando formas de ser e de agir no mundo aos indivíduos. Tais representações não devem ser entendidas como uma mera projeção da realidade produzida pelos grupos, mas sim uma formulação que é fruto de disputas dentro de um determinado grupo social para estabelecer qual a representação que faz jus a uma determinada identidade - e quais representações são interditas, pois não corresponderiam a um ideal identitário. E se é fruto de disputas, significa que as representações são sempre contingenciais e sujeitas à reformulação. No caso religioso, para exemplificar esta relação, podemos enxergar as disputas por representações que ocorrem dentro do campo protestante brasileiro em torno de questões políticas na história recente: 0 fato de a Bancada Evangélica ganhar espaço no Congresso Nacional, encampando pautas morais e sexuais, não significa que todos os evangélicos apoiem estas pautas, ou mesmo que sejam favoráveis ao envolvimento de evangélicos na política partidária. Campanhas divulgadas em período eleitoral como "Diga Não ao Voto de Cajado" (CHUEIRE, 2014), encabeçadas por entidades protestantes como a Rede Fale nos últimos anos mostram que o envolvimento evangélico na política não segue uma única direção, sendo eivado de disputas e tensões internas, que passam pela definição que cada grupo 
em disputa atribui a um ideal de identidade do que constitui o "verdadeiro cristão" ou a "verdadeira cristã" (não raro, distinções de gênero que atribuem lugares sociais e de poder muito diferentes de acordo com o gênero). A História Cultural, ao trabalhar com questões de representações e identidades, também compreendem as diferentes variáveis identitárias - ou interseccionalidades, como recentemente tem se afirmado - tais como classe, nacionalidade, raça/etnia, gênero, sexualidade, religião, dentre outros.

A partir destas concepções, as relações entre religião, mídia e cultura contemplam as produções artísticas, as expressões culturais- enquanto modo de vida - de grupos sociais, as formas de transmissão e de manutenção da tradição, os conflitos internos a uma religião lutam para que determinados grupos tornem sua visão de mundo, suas representações sobre uma determinada parte da tradição sejam consideradas legítimas (desde as controvérsias no início da cristandade, sobre a natureza de Jesus Cristo, passando pelos conflitos iconoclastas no século VIII - HORSFIELD, 2016, pp.37-66). Além disso, pesquisar cultura significa observar de que forma os agentes religiosos tomam para si a tarefa de moldar sua própria cultura - e de que forma esta tarefa interfere em outras instâncias sociais, políticas, econômicas. Por isso, Morgan (2008, pp.xi$\mathrm{xv}$ ) defende que o conceito de cultura pode ser entendido como aquele que interliga os conceitos de religião e de mídia.

Ao lidarmos com a questão da diversidade cultural religiosa, estamos cientes de que há minorias e tradições religiosas que são ainda pouco investigadas no que se refere às suas relações com a mídia ou a comunicação. Muitas pesquisas sobre mídia, religião e cultura ainda versam, no Brasil, sobre religiões cristãs - sendo que que nosso país possui uma pluralidade religiosa que também possui sua história com veículos de comunicação e com formas de expressão cultural e artística ainda pouco exploradas. Essa é um dos nossos maiores desafios atualmente - ampliar nosso escopo de objetos para além do mundo cristão. Outro desafio, que é assunto do próximo tópico, é ampliar a definição de mídia.

\section{0 que é mídia e religião?}

Deixamos o conceito de mídia por último, a fim de demonstrar alguns trabalhos feitos na área de mídia, religião e cultura, e como a problematização da definição de mídia tem sido útil para a ampliação dos tipos de enfoques desenvolvidos nos últimos anos. O termo mídia surge nos anos 1920 (BURKE e BRIGGS, 2004), no contexto da crescente popularização de certos veículos de comunicação de massa no hemisfério norte - o cinema, o rádio, a mídia impressa, o telegrama. 
Durante muito tempo, por praticamente todo o século $X X$, os estudos de religião e os estudos de mídia ignoraram-se mutuamente (HOOVER, 2006; MORGAN, 2008), ou seja, dificilmente os estudos de religiões levaram em conta seus fenômenos comunicacionais, assim como os estudos de mídia raramente consideraram a religião dentre seus estudos, a despeito de muitos fenômenos de comunicação emprestarem características de rituais coletivos (como 0 cinema e os concertos de música), ou estarem permeados por símbolos e narrativas religiosas em produtos de entretenimento. Do lado dos estudos de mídia, essa exclusão reflete o paradigma da secularização predominante nas ciências humanas no século $X X$, e que relegou a religião ao âmbito privado, como um aspecto residual de uma ordem pré-moderna que viria a desaparecer com 0 avanço da modernização. Mas como explicar a presença religiosa nos âmbitos privado e público ao longo de todo o século passado? Esse é um forte indício que tem refutado a eficácia de tal secularização, em especial em países como o Brasil.

Por sua vez, os estudos norte-americanos de mídia, religião e cultura, em especial de Stewart Hoover, têm trabalhado com o conceito "midiatização da religião" (HOOVER, 2006; 2014) para atestar que a dimensão religiosa está enredada nas estruturas da mídia - em especial nos contextos mais recentes, em que a comunicação está dominada pelas mídias digitais. Isso significa que as religiões se adaptam às estruturas simbólicas e linguísticas das mídias, a fim de manterem a comunicação com seus fiéis, e com a sociedade que não pertence ao seu círculo.

A midiatização da religião não significa a mera utilização das mídias para a transmissão de mensagens religiosas, mas sim a incorporação de formatos de comunicação midiática pelas autoridades religiosas e por seus fiéis, ressignificando as experiências religiosas e as maneiras como as tradições religiosas lidam com o mundo que não é religioso e/ou não compartilha de sua crença. Isso pode ser observado desde a ascensão de religiosos à condição de celebridade pelos usos de mídias digitais, com Pe. Reginaldo Manzotti, pe. Fábio de Melo, Ana Paula Valadão, Silas Malafaia, Monja Cohen, Dalai Lama, dentre muitos outros. Mas também pode ser visto em tempos anteriores às mídias digitais, como por exemplo, o próprio impacto da imprensa de Gutemberg na expansão do protestantismo, com a publicação da Bíblia no vernáculo no século XVI, ou ainda, a expansão das revistas e jornais publicados por grupos religiosos nos Estados Unidos do século XIX, mediante o barateamento do papel e das técnicas de impressão (COHEN, BOYER, 2008; MORGAN, 1999). Tais iniciativas possibilitaram não somente a transmissão de crenças religiosas, mas a formação de uma comunidade de fiéis/leitores a partir dos impressos. 
Mas sem dúvida, as mídias digitais conferem um aspecto diferente à comunicação no âmbito religioso - institucionalizado ou não. Seja por conta da possibilidade de maior interatividade entre lideranças e fiéis; seja pela criação e canais de comunicação e interação entre os fiéis, alternativos aos meios oficiais; seja pela incorporação de tais meios pelas instituições religiosas no seu cotidiano, dentre outros fatores. A midiatização nesse contexto recente não se limita, portanto, aos "usos" instrumentais da mídia por instituições ou agentes religiosos, mas uma gama complexa de interações entre o campo religioso e o campo de mídia. Nesse contexto são observados também exemplos de circulação de mensagens e práticas religiosas produzidas por agentes independentes, e que mobilizam um considerável público - a literatura de autoajuda, com best-sellers católicos, evangélicos, espíritas, de "Nova Era", dentre muitos outros, é um caso notório também de midiatização religiosa.

Mas será que todas as religiões do mundo se mediatizam ao caminharem para o século XXI? Haveria religiões mais propensas à midiatização, seja pela sua constituição institucional, ou pelas suas crenças, ou condições históricas específicas? O contrário também existiria - religiões menos propensas à midiatização - por conta de sua organização, ou por determinados momentos históricos? Seria um destino inexorável ao campo religioso como um todo, ou podemos enxergar a midiatização a partir de outro prisma - 0 das relações históricas entre religião e comunicação? A relação entre comunicação e religião sempre foi rica e multifacetada, englobando a presença de imagens, arquitetura, cultura oral (cânticos, orações, preces, sermões, música instrumental etc.), cultura audiovisual, cultura visual, cultura material, que vai das procissões da Idade Média, dos vitrais das igrejas, passa pelas rezas de benzedeiras e seus rituais de cura, segue pelos pontos da umbanda, e vai até as feiras de exposição de produtos católicos e evangélicos - a Expo Católica e a Expo Cristã, que ocorrem na cidade de São Paulo desde o início dos anos 2000. Assim, 0 conceito de comunicação parece nos oferecer uma dimensão mais complexa de possibilidades de pesquisa, pois compreende tanto os meios/veículos de comunicação como as relações que elas possibilitam - desde a conversa cara a cara até as intrincadas comunicações digitais da atualidade.

Portanto, a religião pode ser compreendida nos detalhes da vida cotidiana - aspecto da vida social que, segundo o historiador Michel de Certeau (1998), está sujeito à invenção dos indivíduos, e não, à mera repetição ou reprodução de gestos e gostos. Podemos enxergar estas manifestações nos trabalhos de Colleen McDanell (1995), sobre o cristianismo material norteamericano; de Birgit Meyer (2015) e seu grupo de estudos na Holanda, sobre as dimensões sensacionais ou sensoriais das religiões a partir da antropologia; o trabalho sobre piedade e cultura 
visual do historiador David Morgan (1999); o trabalho de Magali Cunha sobre os sentidos da cultura gospel (2007); os trabalhos de Brenda Carranza (2011) sobre o catolicismo midiático; as pesquisas de Jorge Miklos (2014), Luis Erlin (2018), Renata Cardias (2016), Alexandra Gonsalez (2016) sobre folkcomunicação, cultura material e imagética religiosa popular; os trabalhos de Ricardo Freitas de Oliveira (2010) sobre as relações entre as religiões de matriz africana e os veículos de comunicação; meus trabalhos sobre cultura visual e material infantil (BELLOTTI, 2010) e juvenil (BELLOTTI, 2012) no campo evangélico brasileiro e norte-americano, dentre muitos outros trabalhos. Boa parte dos trabalhos produzidos mundialmente não estão traduzidos para 0 português - mas muita pesquisa tem sido produzida em nosso país, com referencial nacional e estrangeiro (BELLOTTI, 2012; CUNHA, 2016).

Há ainda uma predominância de estudos realizados sobre religiões cristãs, mas pelos exemplos acima vemos que as possibilidades exploradas não se restringem a discursos oficiais e institucionais. É importante, contudo, que estudos sobre outras religiões, não cristãs, sejam conduzidos, a fim de problematizar as formas como a comunicação tem se relacionado com as práticas religiosas de diferentes tradições, a fim de verificar se as religiões se modificam ao incorporar diferentes tipos de comunicação; e de maneira isso ocorre (e com quem ocorre), no caso afirmativo. No caso de uma resposta negativa a esta pergunta, quais as resistências à comunicação - ou a determinados tipos de comunicação/mídia; quando isso ocorre; e quem se responsabiliza por isso.

Outro campo a ser mais explorado são os estudos sobre as abordagens de elementos, narrativas, instituições e personagens religiosos e espirituais presentes na chamada mídia "secular" - e quão secular é esta mídia. Um exemplo disso são as coberturas jornalísticas feitas sobre assuntos e personagens religiosos - enquanto o catolicismo sempre teve prominência nas coberturas jornalísticas da grande imprensa secular no Brasil (CUNHA, 2016), outras religiões sempre oscilaram entre a invisibilidade e a representação depreciativa. Ainda está para ser feito no Brasil um estudo de fôlego tal como feito por Stewart Hoover sobre a relação entre imprensa e religião nos Estados Unidos, no livro "Religion in the News" (1998). Ou ainda a relação entre o consumo de mídia e a pertença e prática religiosa das famílias, em pesquisa organizada por Stewart Hoover, Lynn Clark e Diane Alters entre diferentes configurações familiares e religiosas dos Estados Unidos, "Media, Home and Family" (2003).

Aliás, os estudos sobre recepção e consumo de mídia com conteúdo religioso são um dos maiores desafios para quem estuda este campo, seja pela dificuldade em obter dados - quando se parte para pesquisas etnográficas -, seja pela abundância de dados -quando se refere à 
investigação nas mídias digitais. Nesse sentido, Magali Cunha (2017) realizou um trabalho instigante sobre a presença de lideranças e formadores de opinião evangélicos nas redes sociais. Enfim, as opções de objetos e problemáticas parecem infinitos, à medida que os/as agentes religiosos criam diversas expressões e relações comunicativas -e à medida que ampliamos nossos olhares para tais expressões e relações em outras temporalidades.

Há quem critique -de maneira um tanto inconsistente, sem demonstrar explicitamente a quais trabalhos se refere (GAUTHIER, 2014, pp. 71-88) -, que os estudos de religião e mídia concentram-se demais em análises de casos, sem se referir a contextos mais amplos. $O$ autor em questão propõe determinadas conceituações contemporâneas para explicar certas tendências religiosas que se relacionam ao contexto recente de expansão do neoliberalismo e da globalização - sem problematizar as profundas desigualdades que perpassam esses fenômenos. Assim, ele vincula a midiatização religiosa a uma neoliberalização religiosa - isto é, as religiões estariam sujeitas aos mesmos fenômenos do neoliberalismo econômico, tais como a desregulação, 0 individualismo e o consumismo. É inegável que estas características podem ser observadas no âmbito brasileiro, por exemplo. Mas não seriam os estudos de caso importantes para verificar outras experiências, que muitas vezes escapam ou até resistem a este suposto fenômeno global? Seria possível, ousando um pouco mais, pensar em epistemologias latino-americanas, africanas, asiáticas, entre outras, dos estudos de religião, mídia e cultura? Fica o desafio aos nossos leitores para testar estas provocações.

\section{Referências}

AGNOLIN, Adone. O Debate entre História e Religião em uma breve História das Religiões: Origens, Endereço Italiano e Perspectivas de Investigação. Projeto História, São Paulo, n.37, p. 13-39, dez. 2008.

ASSMANN, Hugo. A Igreja Eletrônica e seu impacto na América Latina. Petrópolis: Vozes, 1986.

BELLOTTI, Karina. Kosicki. "Delas é o Reino dos Céus" - Mídia evangélica infantil na cultura pósmoderna do Brasil (anos 1950-2000). 1. ed. São Paulo: Annablume / Fapesp, 2010.

Evangelical Media for Youth and Religious Authority in Brazil. In: HOOVER, Stewart M.. (Org.). The Media and Religious Authority. 1ed.Pennsylvania: The Pennsylvania State University Press, 2016, v. 1, p. 209-227.

BELLOTTI, Karina. Kosicki.; CUNHA, Magali. do Nascimento. (orgs.) Mídia, Religião e Cultura Percepções e Tendências em Perspectiva Global. Curitiba: Prismas, 2016.

BLOCH, Marc. Apologia da História ou O Ofício do Historiador. RJ: Jorge Zahar, 2001. 
BRELICH, Angelo. Encyclopédie de la Pléiade, Histoire des Religions. Ed. Gallimard, 1970, p. 3$12 ; 57-59$.

BURKE, Peter; BRIGGS, Asa. Uma História Social da Mídia: De Gutenberg à Internet. RJ: Jorge Zahar, 2004.

BURKE, Peter. "Unidade e variedade na história cultural" In: Variedades de história cultural. RJ: Civilização Brasileira, 2000, pp. 231-268.

O que é história cultural?. RJ: Jorge Zahar, 2008, $2^{\mathrm{a}}$ ed. rev. ampl.

CAMPOS, Leonildo Silveira. Teatro, Templo e Mercado. Petrópolis; São Paulo: Vozes-Umesp, 1997.

CANCLINI. Néstor. Culturas híbridas. SP; EdUSP, 4ª .ed., 2015.

CARRANZA, Brenda. Catolicismo midiático. Aparecida: Editora Idéias \& Letras, 2011.

CAVA, Ralph. Della; MONTERO, Paula. E o Verbo se faz Imagem: Igreja Católica e os Meios De Comunicação no Brasil, 1962-1989. Petrópolis: Vozes, 1991.

CERTEAU, Michel de. A Invenção do cotidiano - as artes de fazer (vol.1). Petrópolis: Vozes, 1998, $3^{\mathrm{a}}$. Ed.

CHARTIER, Roger. "O Mundo como Representação" In: À beira da falésia. POA: EdUFRGS, 2003, pp. 61-79.

CHUEIRE, Carol. Campanha combate 0 "voto de cajado" em igrejas. https://www.ultimato.com.br/editora/conteudo/campanha-combate-voto-do-cajado-em-igrejas. Ultimato online. Publicado em 16 de setembro de 2014. Acesso em 25 de novembro de 2018.

COHEN, Charles. \& BOYER, Paul; (orgs.). Religion and the culture of print in Modern America. Madison: The University of Wisconsin Press, 2008

CUNHA, Magali do Nascimento. A explosão gospel: um olhar das ciências humanas sobre 0 cenário evangélico no Brasil. Rio de Janeiro: Mauad X, Instituto Mysterium, 2007.

Digital. Curitiba: Prismas, 2017. Do púlpito às mídias sociais: Evangélicos na Política e Ativismo Religião no noticiário: marcas de um imaginário exclusivista no jornalismo brasileiro. Revista da Associação Nacional dos Programas de Pós-Graduação em Comunicação - E-compós, Brasília, Jan/Apr. 2016, v.19, n.1.

GAUTHIER, François. "Religion, Media and the Dynamics of Consumerism in Globalising Societies" In Granholm, K. et allii, eds, Religion, Media, and Social Change. New York, NY: Routlegde, 2014, pp. 71-88.

GEERTZ, Clifford. A Interpretação das Culturas. RJ: LTC, 1989. 
GONSALEZ, Alexandra. Nossas Senhoras do Brasil - as principais igrejas e representações de Maria. Pólen Livros, 2016.

GORDO, Luís. Comunicação (I) material com as divindades - tipos e formas de ex-votos na religiosidade popular. Tese de Doutorado em Comunicação Social. São Bernardo do Campo: Umesp, 2018.

HOOVER, Stewart:; MERELMAN, Richard. Making Something of Ourselves: On Culture and Politics in the United States. Journal for the Scientific Study of Religion. 24(3):337, September 1985.

HOOVER, Stewart. Religion in the News - Faith and Journalism in American Public Discourse. London: SAGE Publications, 1998.

\& CLARK, L. (eds.). Practicing Religion in the Age of the Media - Exploration in Media, Religion, and Culture. New York: Columbia University Press, 2002.

Religion in the Media Age. London/New York: Routledge, 2006.

Mídia e religião: premissas e implicações para os campos acadêmico e midiático. C\&S - São Bernardo do Campo, v. 35, n. 2, p. 41-68, jan./jun. 2014.

HORSFIELD, P. Religious television: the American experience. Longman, 1984.

The Media and Religious Authority from Ancient to Modern. In: Hoover, S.M., (ed.). The Media and Religious Authority. University Park, PA: The Pennsylvania State University Press, 2016, pp. 37-66.

HUNT, Lynn. (org.). A Nova História Cultural. São Paulo, Martins Fontes, 1995.

KAWAGUCHI, Renata. "As festas como processos comunicacionais: identidade e religiosidade popular nas comunidades quilombolas" In BELLOTTI, K. K.; CUNHA, M. do N.(orgs.) Mídia, Religião e Cultura - Percepções e Tendências em Perspectiva Global. Curitiba: Prismas, 2016, pp. 315-344.

KELLNER, Douglas. A Cultura da Mídia. Bauru-SP: Edusc, 2001.

McDANNELL, Colleen. Material Christianity, Religion and Popular Culture in America, Yale University Press, 1995

MEYER, Birgit. Mediação e Imediatismo: formas sensoriais, ideologias semióticas e a questão do meio. Campos Revista de Antropologia Social. UPFR, v.16, n.2 (2015).

MIKLOS, Jorge. Cultura e Desenvolvimento Local: Ética e Comunicação Comunitária. São Paulo: Saraiva, 2014.

MORGAN, David. (ed.). Key words in Religion, Media and Culture. New York: Routledge, 2008.

Protestants \& Pictures. Protestants and Pictures: Religion, Visual Culture, and the Age of American Mass Production. New York: Oxford University Press, 1999. 
OLIVEIRA, Ricardo. Religiões Afro-Derivadas na Web: Cyberterreiros e Afrodiáspora Global. RECIIS - R. Eletr. de Com. Inf. Inov. Saúde. Rio de Janeiro, v.4, n.3, p.70-80, Set., 2010.

WILLIAMS, Raymond. Palavras-chave: um vocabulário de cultura e sociedade. SP: Boitempo, 2007.

Cultura e Sociedade - 1780-1950. SP: Companhia Editora Nacional, 1969. 